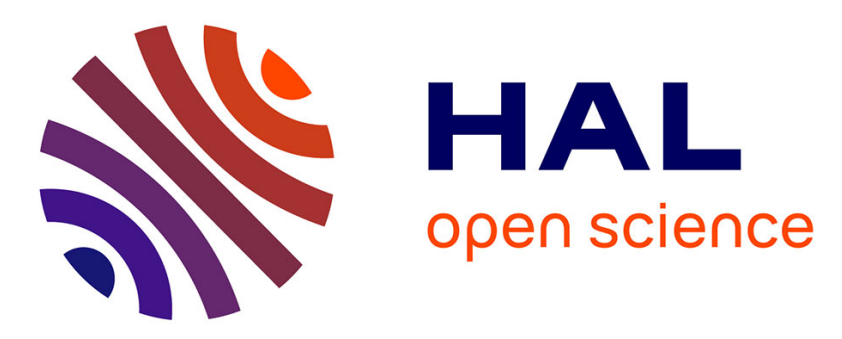

\title{
Nightlife Tourism: A Blessing or a Curse for Host Communities? "A Case Study on Gemmayzeh, Lebanon"
}

\author{
Hanna El Maalouf, Socrat Ghadban, Maya Shames
}

\section{To cite this version:}

Hanna El Maalouf, Socrat Ghadban, Maya Shames. Nightlife Tourism: A Blessing or a Curse for Host Communities? "A Case Study on Gemmayzeh, Lebanon". Journal of Tourism Research \& Hospitality, 2015, 4 (2), 10.4172/2324-8807.1000147 . hal-01335594v2

\section{HAL Id: hal-01335594 \\ https://hal.science/hal-01335594v2}

Submitted on 12 Jul 2016

HAL is a multi-disciplinary open access archive for the deposit and dissemination of scientific research documents, whether they are published or not. The documents may come from teaching and research institutions in France or abroad, or from public or private research centers.
L'archive ouverte pluridisciplinaire HAL, est destinée au dépôt et à la diffusion de documents scientifiques de niveau recherche, publiés ou non, émanant des établissements d'enseignement et de recherche français ou étrangers, des laboratoires publics ou privés. 


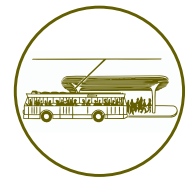

\section{Journal of Tourism Research \& Hospitality}

\section{Nightlife Tourism: A Blessing or a Curse for Host Communities? "A Case Study on Gemmayzeh,
Lebanon"}

Hanna El Maalouf*, Socrat Ghadban and Maya Shames

\begin{abstract}
Gemmayzeh is located in Beirut Central District, known to be one of the most famous night attractions in the Lebanese capital. It is also a special attraction for domestic visitors and tourists. However, despite its competitive nightlife advantages in the Lebanese tourism industry, its local residents are not convinced with the way tourism is being developed in this area. The lack of cooperation among the different potential tourism stakeholders and the absence of effective regulations and policies have affected the traditions and heritage of the local residents especially that this specific region is one of the oldest in Beirut with many historical and cultural buildings. All these vibes have created negative impacts on the community's well-being The absence of tourism planning is affecting most of the Lebanese tourism attractions and it is getting worse with time especially in the case of Gemmayzeh whose residents have been involved in direct conflicts with visitors and are trying to avoid the negative impacts on their children at times. Therefore, this study aims to review the impacts of tourism development on Gemmayzeh's local residents, to assess and analyze the type of involvement of local communities in tourism planning and development and to explore the attitudes and perceptions of local residents towards tourism development and its impacts on the community. Out of 1,400 permanent local residents in Gemmayzeh, 50 respondents (representing $5 \%$ of the target population) were selected and surveyed during January, 2014. Results have revealed that the lack of involvement of local residents in tourism planning and development has negatively affected their perception towards tourism development. Although this issue is affecting the local community, results revealed that the majority of respondents, mainly young ones, have no problem with nightlife as a type of tourism but with the way it has been developed for years. Furthermore, respondents suggested the development of other forms of tourism such as cultural tourism which can have a better impact on all stakeholders.
\end{abstract}

\section{Keywords}

Tourism development; Nightlife tourism; Gemmayzeh; Loca community involvement; Socio-cultural tourism impacts; Stakeholder collaboration

Abbreviations: DMO: Destination Marketing Organizations; TALC: Tourism Area Life Cycle; QOL: Quality of Life; GCl: Global Competitiveness Index; WTTC: World Travel and Tourism Council

*Corresponding author: Hanna El Maalouf, Department of Tourism and Hospitality Management, Lebanese University, Beirut, Lebanon, Tel: 00961-3 595404; E-mail: hannamaalouf@hotmail.com

Received: May 27, 2015 Accepted: August 10, 2015 Published: August 14 2015

\section{Introduction}

"Tourists view tourism destinations as one whole composed of different elements, like a puzzle, each element in a puzzle is a tourism stakeholder with specific interests and different roles and abilities" [1]. According to this quote, it is assumed that if any of these stakeholders is out of place, it will negatively end up affecting the overall tourism image. This identifies the reason it is essential for a tourism area to hold every aspect needed for positive interaction and collaboration between tourism stakeholders. The performance of a tourism destination depends primarily on the type of collaboration among the different tourism stakeholders who are mainly presented by tourists, tourism service providers, local residents and Destination Marketing Organizations-DMO. For tourism to be successful and for it to bring benefits for destinations, stakeholders should work in synergy and under the same tourism policy. However, this is not always the case, does not represent the reality on the field, because tourism stakeholders are in most cases in direct conflict following their different interests, and benefits [2]. The involvement of local residents as "major tourism actors" in tourism development is hardly a new issue. Many scholars and researchers have discussed its importance in tourism management and the impacts it has on the performance of a specific tourist destination. From the decision makers' point of view [3], suggested that the stakeholders' participation, particularly the local community's involvement in development, can help in solving many issues. First, taking into consideration the interests of the host communities can help positively affect the area instead of leaving major decisions to parties from outside the region. Second, the participation of local residents can help avoid conflicts with visitors. Because the power of the local communities to influence decision making as well as policy making will therefore depend on the level of participatory approaches being in operation in a particular destination. Finally, it has been argued that tourism planning cannot succeed if local residents are not involved in the planning process (Byrd, 2007; Andriotis and Vaughan, 2003). The level of local residents' participation in tourism planning and development can differ from one member to another. According to Mannigel [4], there are different levels of participation ranging from simple sharing of information to a full transfer of power and responsibilities for the locals. Moreover, tourists are affected by this involvement as well. In fact, many tourists visit specific destinations only to meet local people and get to know their culture and traditions; thus, visitors will always have a direct contact with the local residents which will then influence their overall tourist experience. However, if these locals do not participate, the visitor will not be satisfied which will negatively affect their stay and experience and vice versa (Ko and Stewart, 2002). If tourism is well developed and maintained [5], the positive impacts of tourism can be very beneficial for the residents affecting their quality of life. These impacts also help in decreasing poverty and increasing job opportunities, promoting social equity, raising standard of living, peace building and reducing stereotyping, and increasing pride among local residents. However, the socio-cultural negative impacts of tourism such as cultural clashes, loss of identify and local values, and changes in local products to satisfy tourist demand, generally appear when tourism is being imposed on the local community or developed to satisfy the needs and wants of tourism leaders only for 
financial or political reasons [6]. However it is worth mentioning that the perception of impact differs from one person to another. The same impact can be seen as negative by one person and positive by others of the same community. Moreover, the level of tourism impact can differ between one destination and another depending on the level of development of the destination. It is known that negative outcomes are more likely to be seen in developing or under developed countries, while positive outcomes are generally more common in developed countries because of the regulatory framework adopted and implemented and the maturity of the tourism sector [7]. Another factor affecting the community relation with tourism is the type of tourism created in this specific region as stated by Palomino (2003). For example, some types of tourism such as nightlife tourism [8], sex tourism and other forms of mass tourism are all considered as sensitive types which can all contribute to social changes and affect the quality of life of local residents. For instance, recently, urban planners and scholars have noted the preponderance of "destination nightlife", "nightscape" or "no-go" zones. Within these "no-go" entertainment zones, it is assumed that the police have an increasing challenge in maintaining order and protecting residential interests in terms of quality of life or property protection (owing to inappropriate behavior, vandalism, public urination, etc.) [9]. Taking a closer look at Lebanon, it has been named by a number of international media as the number one tourist destination for its unique landscapes, beaches and resorts, and Beirut's vibrant nightlife (IDAL, 2014). Lebanon is a well-known destination in the Mediterranean region, with a very small surface area $\left(10,452 \mathrm{~km}^{2}\right)$. The country is endowed with a special landscape and heritage, and a mild climate that distinguish it from all the neighboring countries. Nevertheless, this small country is facing many problems and challenges including security and political instability with continuous incidents and conflicts every now and then. The crisis in the neighboring countries, such as the current Syrian Civil War, has greatly affected the tourism industry and created conflicts between the Lebanese host communities and the Syrian refugees. For instance, Lebanon is considered as the first country hosting more than 1 million Syrian refugees representing approximately 30\% of the Lebanese population (UNHCR, 2014)[11]. Moreover, the lack of effective tourism policy such as the tourists' code of conduct and the instability of the economic system, are all uncontrollable variables to tourism regulators. Gemmayzeh is a wellknown destination for nightlife tourism in Beirut, and the problems it is facing are the same as many other tourist attractions in Lebanon: The lack of tourism planning and development, in addition to the lack of cooperation among the different stakeholders involved which are represented by the local residents, the mayor of Gemmayzeh, tourists, shops (bars and pubs) owners and the government, all of which have affected the region and the well-being of its residents. The local community in Gemmayzeh is dissatisfied with the way tourism is being developed in their region, and they are uncertain about the future of tourism development.

This study aims to answer the following questions: What are the attitudes and perceptions of the host community in Gemmayzeh toward the socio-cultural tourism impacts?. What role do the local residents play in tourism planning and development? Based on the above questions, this study seeks to explore and analyze the sociocultural impacts of tourism in Gemmayzeh, to discover and assess the type of involvement of local community in tourism planning and development and to explore the attitudes and perceptions of residents toward tourism development and its impacts on the community.

\section{Theoretical Framework}

According to the World Travel and Tourism Council WTTC [12],"The travel and tourism total contribution to the global economy in 2013 rose to $9.5 \%$ of the global GDP". This fact emphasizes the importance of tourism as one of the largest industries in the world, and a main source of income and employment for many people and countries. The positive impacts of tourism have not only affected tourism destinations at a national level, but also the global and international economy by the continuous growth of this sector all around the world.

\section{Stakeholder Approach and Tourism Development}

The stakeholder role with regard to tourism planning and development is one of the most important topics to be examined in this paper in order to understand its impacts on the performance of tourism destinations. The performance of tourism destinations can be measured by the quality of services and facilities provided for tourists and the degree of collaboration between the stakeholders involved (European communities, 2003). Furthermore, the growth of tourism destinations is dependent on the influences between different sectors, the stakeholder relationship dynamics, and the interactions between different levels of governance (Presenza, 2007). In fact, there has been a growing body of literature on the stakeholder approach [13]. Many researchers attempted to study the role of stakeholders in improving the image of tourism destinations. It is first critical to define the term "stakeholders" as "individuals or groups who depend on the tourism organization to fulfill their own goals and on whom, in turn, the organization depends [14]". A tourism organization is any tourism service provider; it has specific and limited number of stakeholders and is concerned with specific types of activities. Applying the concept of stakeholder in the tourism industry, at a larger scale, implies that stakeholders are varied with various needs and conflicting interests. Thus, key stakeholders must be identified first and responsibilities must be assigned accordingly, so that each stakeholder can achieve the specific tasks that will help build a good synergy to create a memorable tourist experience. However, not all stakeholders have the same level of impacts on the performance of the organization. Freeman (1994) was one of the first researches who classified the stakeholders into primary and secondary stakeholders [15]. On one hand, the participation of primary stakeholders including visitors, local residents, competitors, DMO, accommodations and transportation industries, all hold major and direct impacts on the performance of the tourism industry. On the other hand, the secondary stakeholders such as gas stations, media, universities, hospitals, financial institutions, telecommunications, and small businesses have no direct impacts contact on the success of tourism destinations. It is worth mentioning that secondary stakeholders can be primary in situations where their coordination is directly related with the growth of the tourism industry. Thus, the role of stakeholders changes with the changing tourism type [16]. This means that the type of tourism in a specific destination defines the role of each stakeholder involved. Nightlife tourism, for example, which is the core of this study, requires the involvement of local residents who are mainly concerned in nightlife tourism planning and management. Since nightlife tourism brings many changes (mostly negative impacts) to the value system of communities, local residents has a primary role in the development of that type of tourism [17]. Nonetheless, this role should be emphasized by the collaboration of the different stakeholders involved. According 
to Bramwell and Sharman (1999), the effective implementation of stakeholder collaboration has many benefits on the tourism planning and management. First, it can help solving the stakeholder's conflicts. Second, it impacts the decision making process to produce collective actions. Finally, it can end up affecting positively the development of new tourism policies. With the increasing negative impacts of tourism on the local communities, authors have went deeper in analyzing the role of local communities in developing tourism. Muganda et al. (2013) was one of the researchers who examined the views of local communities' members on their role in tourism development in the village of Barabarani, Tanzania. The findings of the study revealed that respondents consider that they should have an interactive role in the decision making process, where their interests can be reflected and incorporated in a way that protects their identity. Furthermore, at the local level, the primary goal of tourism development is essentially to the development of communities. Therefore, tourism should be used as a tool for local residents to develop their societies, which is known as self-help approaches to community development (Aref et al. 2010).

\section{Socio-Cultural Impacts of Tourism}

It is acknowledged that tourism is known to have positive as well as negative impacts on host communities in a given destination. When discussing the concept of nightlife tourism it is important to address the socio-cultural impacts of tourism on host communities. The socio-cultural tourism impacts can be defined as "the effects on host communities of direct and indirect relations with tourists, and of interaction with the tourism industry" [18]. In other words, the impacts of tourism on the local communities are the result of the interaction between local residents, who have specific customs and traditions with different cultural background, and tourists who are not sensitive to the culture of the visited community.

Nightlife tourism has many negative impacts on the societies. It may affect the cultural system and social behavior, the family relationships, the individual behavior, and the collective lifestyles. It risks also the safety levels of the societies, the traditional ceremonies and the continuity of community organizations. Many security issues have appeared in destinations where nightlife tourism exists [19]. According to Zaei and Zaei (2013), the type and level of sociocultural tourism impacts is associated with the cultural and religious strengths of the community. As a result [20], the more community members are attached to their culture the less they are sensitive to tourists and vice versa. Analyzing the tourism impacts on host communities from a different perspective, [21] endeavored to divide social impacts into two categories "real" and "perceived" tourism impacts. The real socio-cultural impacts are defined as "the impacts that can be measured with objective data that verifies its existence". Many examples can illustrate this category including the level of traffic congestion, prostitution caused by the unorganized sex tourism or nightlife tourism. The opposite can be the improvement of the standards of living of a certain community as a result of increasing job opportunities, etc. At the opposite side, the perceived social impact is the impact that is perceived differently by each member of the community, each according to his/her personal views and benefits as well as his/her cultural background. This means that socio-cultural impacts are ambiguous; the same objectively described impacts are seen as beneficial by some groups and as negative by others. From a theoretical point of view Tosun (2002) has examined the relation between tourism impacts and resident's perception toward these impacts. Findings revealed that there is a positive relation between these two variables. Residents who perceive tourism impacts as positive are those who have personal benefits from tourism and tend to support that tourism in their destinations, but those residents are also more likely to report negative impacts. From another perspective, Monterrubio, Belloand (2010) and Chaiklin (2010) [23] argued that the attitude of residents toward tourism development and its impacts is positive when tourism is beneficial to the local community. These two opposite theories show that in one destination the attitude is related to the personal benefits of residents, while in the other it is related to the whole community benefits. This contradiction can be explained by the theory of culture specificity of tourism destinations, which is known as individualism and collectivism. Collectivism is a characteristic of culture that defines individuals as being interdependent and having duties and obligations to other group members. However, individualism defines cultures where individuals are seen as independent and self-reliant (Harry and Michele, 2012). Hence, individuals who belong to destinations characterized by individualism are supported by the theory of Tosun, while those who belong to destinations characterized by collectivism are supported by the theory of Monterrubio and Bello. Although, some countries are considered collectivistic such as Lebanon or individualistic such as United States, considerable regional variation exists (Halh, 2014). Lebanon is generally considered as collectivistic society. Lebanese people have long-term commitment to the members "groups.

\section{Residents' Attitudes and Perceptions Toward Socio-Cultural Tourism Impacts}

The level of tourism impacts on the societies is different according to the varying stages of tourism development. In addition, the attitudes of residents toward tourism change with the increasing level of tourism impacts, a theory that emerged mainly four decades ago through the work of Doxey in 1975 (Andrey, 2013) for the famous Irridex model and the one of Butler in 1980 (Gun and Var, 2007) known as Tourism Area Life Cycle-TALC. Figure 1 explains this changing attitude along the different periods of tourism development and the increasing number of tourists.

Doxey's Irridex index model explains how communities change their reactions toward the increasing number of tourists in their area. It also justifies the attitudes of residents at different growth stages of a tourist destination. In accordance with Figure 1, while being compared to the descending curve of the attitudes of residents toward tourism impacts, the area life cycle stages moves from involvement to consolidation stage where tourism develops to reach maturity and then declines or rejuvenates. At the involvement/exploration stage of the life cycle, residents develop the euphoria approach where visitors are welcomed and have positive attitudes toward tourism, moving up in the tourism life cycle stages. However, residents try to build formal communication with visitor's that is known as apathy approach, arriving at the stagnation stage of tourism development, where tourism is more saturated and crowded. It is here where residents are annoyed and dissatisfied by tourism development and tend to have negative attitudes towards its impacts on their regions [24]. Finally, at the declining stage of tourism development where tourists will then turn for new destination to satisfy their needs affected by different types of crises, residents will tend to develop what is called antagonism and possibly altering their behaviors or simply avoiding visitors. Researchers claim that this model has no end-point; it could even lead to xenophobia where residents become hostile toward tourists or to nostalgia as host's attitudes are subject to ongoing changes dependent on fluctuating tourists numbers. Hence, the relationship between Doxey's index model and Butler 

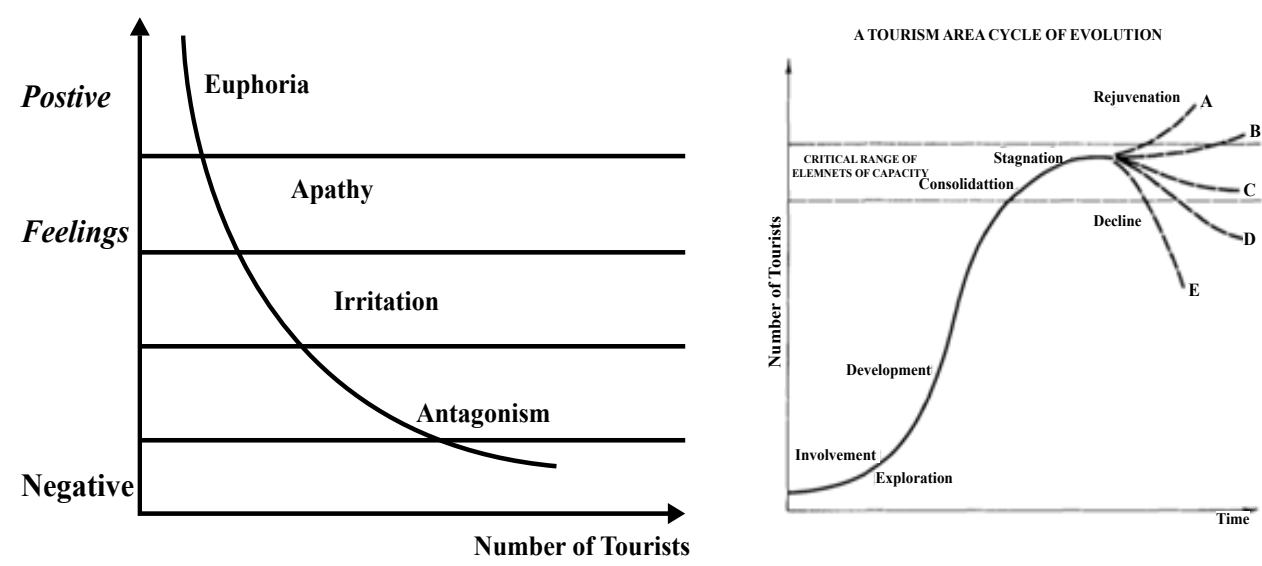

Figure 1: The changing attitude of host communities with the varying stages of tourism development Source: (Andrey, 2013; Gun and Var, 2007).

tourism life cycle can be summarized by saying that as the number of tourists within a tourism destination increases, it puts pressure on the way of life of residents contributing to a negative attitude toward tourism impacts, According to Ap and Crompton (1993), residents tend to develop behavioral strategies to respond to tourism impacts including embracement, tolerance, adjustment, and withdrawal. The development of each of these strategies depends on the level of impacts of tourism on the communities and type of visitors-residents interaction. Yet, the way local residents perceive tourism impacts may be 'contaminated' by community discussion or media attention [25], where tourism businesses and operating sector take advantage of the residents' attitude toward tourism impacts to benefit from tourism without the involvement of community in tourism development. Studies pointed out that the perception and attitudes of residents toward tourism impacts is affected by many factors other than the increasing number of tourists (Johnson and Snepenger, 2003; Kim, 2002). With reference to Johnson and Snepenger (2003), they have conducted four household surveys with about 400 residents in the area of Shoshone County in the northern panhandle of Idaho [26], USA over the 1990s to investigate how the changing demographics and tourism iteration variables explain the changing community opinion toward tourism development. Studies revealed that residents find it difficult to assess and predict the impacts of tourism on their region at the early stages of tourism development/exploration stage, whereas the assessment ability increases with the increasing economic impacts at the involvement and development stages of TALC. In addition to the aforementioned, findings revealed that residents who had good interactions with tourists tend to view tourism impacts as positive and vice versa. Therefore, the relation between tourism impacts and residents' perceptions is a two way streak. The perception of tourism impact affects the acceptance or rejection of tourism and the level of tourism impacts affect the perception of residents. Furthermore, two other variables were initiated in this study "educational attainment of residents and their age". Findings revealed that the higher the educational attainment, the more predisposed towards tourism development locals tend to be. Additionally, older respondents supported tourism development while younger respondents were less supportive. In addition to the above mentioned factors, Kim (2002) claimed that the satisfaction of residents with a particular life domain is a factor that is affected by their perceptions toward tourism impacts. Surveying a sample of 321 respondents in Virginia has allowed the researcher to conclude that the quality of life (QOL) of residents will decrease or increasingly deteriorate with the changing tourism development life cycle and the residents' satisfaction with their overall life domain, which will then increase, or decrease accordingly. Kim has been able to verify that the same type of tourism impacts can be acceptable in certain destination and unacceptable in others. This finding emphasizes on the importance of tourism types as a variable that identifies the perceptions of residents towards tourism impacts. For instance, inconsistent with the case of developing countries, recreational nightlife tourism, as a type of mass tourism targeting mainly young populations is seen in the European countries today regardless of the many problems it brings to the societies as a concept that defines the quality of life of tourists as well as residents [27]. Moreover, in Amsterdam (the Red Light District) and New Orleans residents have accepted this type of tourism and have built positive perceptions toward its impacts. Despite the problems faced concerning the development of nightlife tourism and prostitution in Amsterdam the government has succeeded in making the latter legal in 2000 by imposing and implementing strict rules and regulations to protect the culture of the destinations and bring benefits to the local communities. Nevertheless, local residents in Lebanon have been facing many problems with regard to nightlife tourism. The case of Gemmayzeh that is the study area of this research symbolizes how local residents have built negative perceptions toward tourism impacts because of the lack of cooperation of tourism stakeholders involved.

This study compliments other studies in assessing the impacts of tourism development on host communities and how local residents perceive these impacts and react through. However, to the best of the researchers knowledge, no or very rare tourism research and studies have been made to study the impacts of nightlife tourism on the Lebanese communities. Marketing have been made instead to attract tourists to the Lebanese nightlife tourism attractions, which makes this study unique in the Lebanese context. This paper also extends the published work by examining three aspects of this topic within one study framework; the purpose is to come up with constructive results for tourism stakeholders in Gemmayzeh to develop more effective strategies.

\section{The Share of the Tourism Industry in the Lebanese Economic Sector}

The Lebanese economy is known by its open market, perfect labor and capital mobility. The private sector constitutes $75 \%$ of 
the aggregate demand and is present in all sectors from providing electricity to managing public services such as telephone and public transport, as well as owning and managing resorts ... This makes the Lebanese economy resilient and allows it to grow despite the political instability. Moreover, the Lebanese economy relies mainly on the service sector, which constitutes $60 \%$ of GDP. Within the Arab countries stages of development, Lebanon occupies a low level of competitiveness even behind the Gulf countries. However, within the Global Competiveness Index-GCI, Lebanon occupies the 91st position out of 144. The reasons behind this ranking are: the underdeveloped infrastructure, the country's difficult macroeconomic environment. Institutions suffer from corruption and the inefficient government agencies (World Economic Forum, 2013). The role of the government in Lebanon is to facilitate the investment in tourism facilities such as the infrastructure, the transportation, the electricity, and other public facilities. Additionally, it aims at promoting tourism and improving the country' image domestically and internationally through the work of the ministry of tourism in Lebanon [28]. The tourism industry in Lebanon is one of the major contributors to the local economy and a main source of revenue generation and employment. According to the WTTC, in 2013, the direct contribution of the tourism industry to the GDP in Lebanon is $6.9 \%$ and the total contribution for the same year registered 19.2\%. Moreover, the Lebanese tourism industry generated 92,500 jobs which constitute $6.7 \%$ of total employment (WTTC, 2014). Nightlife tourism in Lebanon represents a major tourism form which is more concentrated in Beirut. According to the CNN Beirut is considered to be the Middle East party capital which explains the liberal, tolerant attitude towards drinking and the cosmopolitan aspect of the city [29]. Although the current situation of the Lebanese economy suffers from an unstable political situation and a lack of supportive infrastructure, the entrepreneurial culture among Lebanese appears to be robust with almost a quarter of the adult population owns businesses. This fact led to the development of the nightlife tourism in Gemayzeh area based on personal initiative and absence of public sector planning [30].

\section{Gemmayzeh: General Overview}

Gemmayzehis known to be one of the main nightlife hotspots in Lebanon. It is considered as a strong competitor in the Lebanese recreational tourism market, competing Hamra region and Downtown Beirut. It also represents an attractive venue for contemporary art The area is located in East Beirut close to downtown and it is a small, old region in Ashrafieh district (Figure 2). Its territory has an area of 40 hectares constituting $13.3 \%$ of the total area of Ashrafieh and 2\% of Beirut's total area [31]. It is characterized by its traditional style encompassing beautiful historical buildings which date back to the French era.

The most famous street in Gemmayzeh is Gouraud Street (Figure 3). The name originated from the general Henri Gouraud who signed a decree proclaiming the creation of the state of Lebanon in 1920. The street includes a variety of 80 bars and pubs, and 100 cafés and restaurants. Gemmayzeh has a total population of 2,000 residents, among which $70 \%$ are permanent (1,400 persons). Permanent residents in Gemmayzeh can be defined as those who live permanently in Gemmayzeh, meaning that Gemmayzeh is their permanent residence all year round. About $90 \%$ of the local residents work outside Gemmayzeh in the Lebanese public and private sector. This implies that the local residents are not benefiting from tourism and are not contributing to the development of the local economy. Leaving the area to be controlled by foreign investors (Nassar, 2014: personal communication). Stakeholders at Gemmayzeh are divided into two parts: the first part is represented by those who are directly developing and managing nightlife tourism. Those include: the shops' owners and tourists. The second part is represented by those who have partial contribution to tourism development and have less control on tourism management. These are: the local residents, the Lebanese government and the mayor of Gemmayzeh. The role of Lebanese government was ineffective, no rules and regulations were developed to maintain a balanced and equitable tourism growth. Furthermore, the government has failed in implementing effective policies and no regulations have been imitated to guide tourism development, manage tourists' behavior and protect the socio-cultural assets of the local residents. There is no municipality at Gemmayzeh, the district in under the governance of Beirut municipality. The local elected board is represented by the mayor "Elie Nassar" who is also the head of the residents' committees whose role is to create a network of communication between the local residents, to solve local issues and to advocate for the rights of residents. Historically, the city has witnessed two different lifestyle periods, which could be summarized by the eras before and after nightlife tourism development. Tourism entered the stage of exploration in 2006. This year was considered as the turning point for tourism in Gemmayzeh. Before 2006, the city was considered to be a quiet and residential area; it was called the "sleepy neighborhood" with a traditional character. However, tourism reached its maturity stage by 2007 after a rapid and unplanned tourism development (Executive staff, 2008).

The rapid growth of mass tourism in Lebanon and the unplanned tourism projects in Gemmayzeh particularly has resulted in many negative impacts in the area:

- The identity and well being of local residents was affected by the lack of tourism projects aiming at conserving the heritage and traditional character of the region [34]

- Noise pollution caused by loud music until early hours of the morning, the unavailable parking spaces, and the waste left behind by visitors [35]

- Some of the local residents have left the area as a result of the increasing tensions between the local residents, foreign visitors and bar owners.

As a result, the local residents in Gemmayzeh took many initiatives to face the increasing negative impacts of tourism. These included: demonstrations, protests, participating in TV programs and complaints for the Lebanese government and the municipality of Beirut as well as the many attempt to protect the historical buildings from being deteriorated for tourism purposes, in addition to their willingness to participate in tourism planning and management. The most significant act taken by the Local residents in Gemmayzeh was the demonstration in the 31th of March 2008, where residents lodged formal complaints with the Ministry of Tourism and the Governor of Beirut about the problems caused by the bars. As a result the minister of tourism at the time, Minister Fadi Abboud issued a decision onthe $6^{\text {th }}$ of April, 2008 to temporary close some twenty establishments that were not in possession of the correct licenses. Nine clubs reopened after their owners agreed to follow long ignored regulations regarding soundproofing and closing hours [36]. From 2009 until today and after many attempts to control tourism and security in the

${ }^{1}$ The categorization of stakeholders at Gemmayzeh into two parts is based on studies on Gemmayzeh stakeholders done at Lebanon, the faculty of tourism and hospitality management by master two students. 
Citation: El Maalouf H, Ghadban S, Shames $M$ (2015) Nightlife Tourism: A Blessing or a Curse for Host Communities? "A Case Study on Gemmayzeh, Lebanon". J Tourism Res Hospitality 4:2

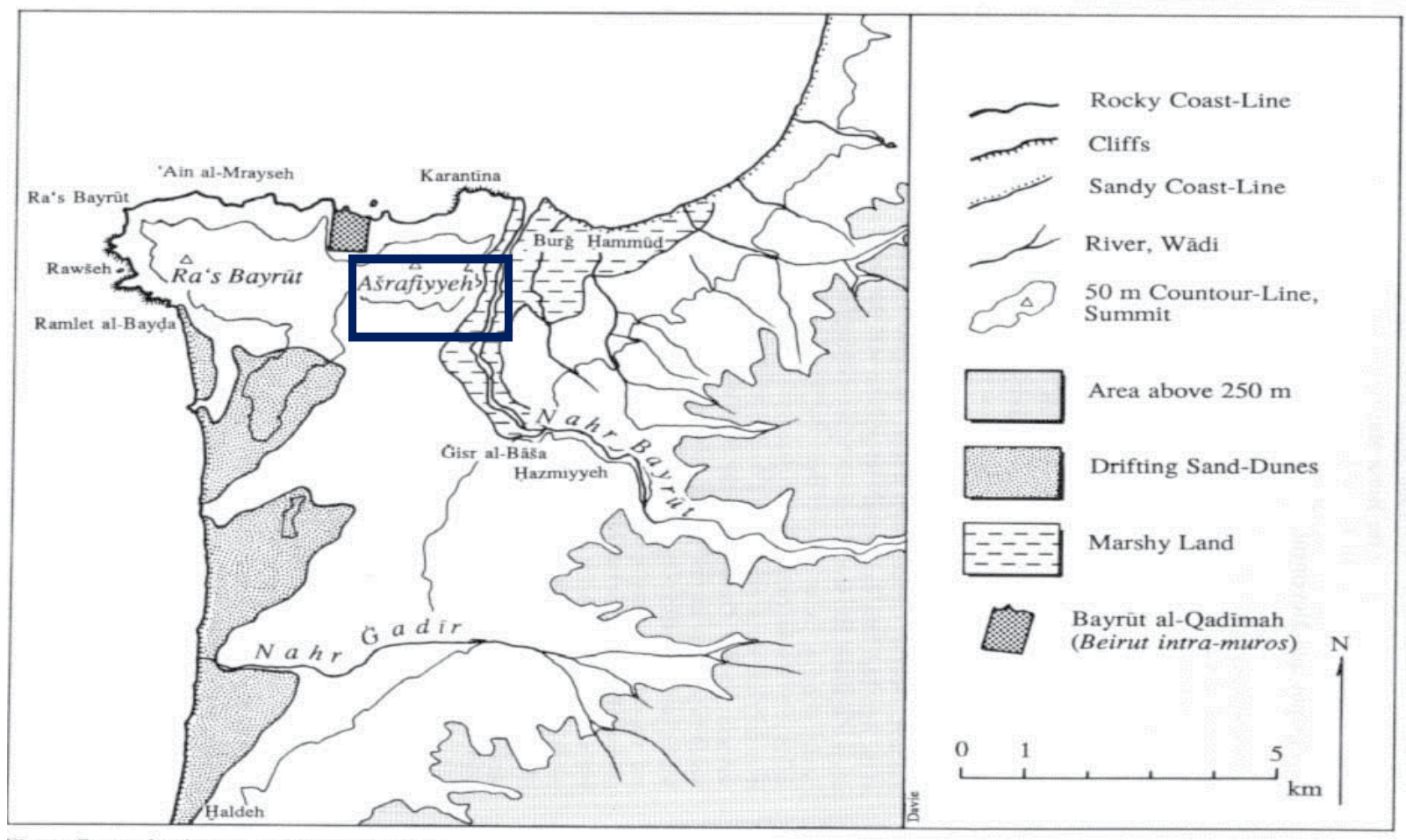

Figure 2: Gemmayzeh is located within the district of Ashrafieh Source: (Davie, 1987).

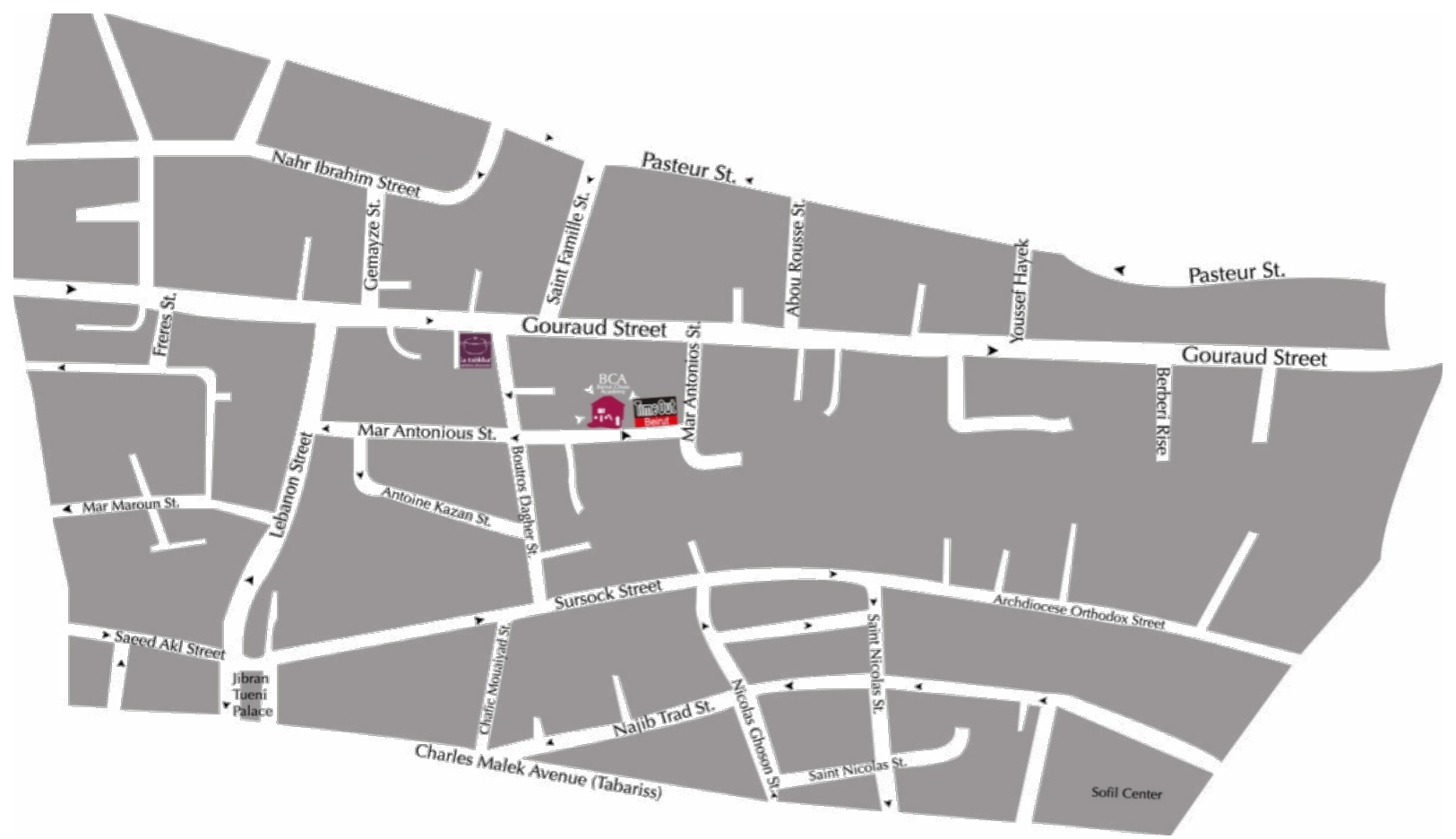

Figure 3: Gemmayzeh district Source: (Beirut municipality, 2014). 
Citation: El Maalouf H, Ghadban S, Shames M (2015) Nightlife Tourism: A Blessing or a Curse for Host Communities? “A Case Study on Gemmayzeh, Lebanon'. J Tourism Res Hospitality 4:2

district taken by the government in the form of decisions issued and bars regulations. In addition to the actions of the Lebanese police to control tourists' behavior. Gemmayzeh is still facing the same problems, the lack of cooperation between the different stakeholders who are not performing their responsibilities and tasks effectively have created real problems for residents. Visitors are not respecting the traditions of the destination. Moreover, the tourism business owners who are from different Lebanese regions are not respecting The law of "General Conditions for the Investment and Development of Touristic Establishments" n ${ }^{\circ} 4221 / 2000$. The law states that no bars are allowed to be in residential buildings, there should be 40 meters between one bar and the other, and 100 meters between bars and schools $^{2}$ [37]. This is physically impossible in Gemmayzeh because it cannot accommodate 80 bars under these conditions. Hence, the law is not yet implemented and no follow up from the government is recognized. Recently, many cultural attractions opened to fill in the city's cultural gap such as the Enthusiastic Art on 56th gallery opened in November 2012 in a historical building in Gemmayzeh.

${ }^{2}$ The Lebanese law regarding the establishment of bars and pubs clearly states that it is not allowed to open bars and pubs in residential buildings. However, the only exception that allows bars to open in residential buildings which entrance is 100 meters away from hospitals, religious institutions and schools.
It focuses on contemporary painters, and represents both local and international artists mixing between different cultures and creative works (Lebanon articles, 2014). Additionally, a new documentation center known as Dawawine opened in the heart of Gemmayzeh and is a non-profit documentation space. The center includes a library and a bookshop dedicated to the lovers of music, theater, dance and cinema (Lebanon traveler, 2014).

\section{Research Methodology}

A qualitative approach was first adopted in the form of a literature review using the analysis of different theories. Additionally, different case studies worldwide were also used to study the nature of the problem in various contexts. Based on the indicators of the literature review, the survey questionnaire was developed and conducted. The conceptual framework (Figure 4) was developed based on tourism development theories and the actual situation of nightlife tourism in Gemmayzeh. This figure explains the two-way relations between three different concepts as discussed in the literature review: tourism development, nightlife tourism and socio-cultural tourism impacts [38]. The attitudes' variables explored within the study framework include the attitude toward nightlife tourism development, increasing number of tourists, tourism impacts and the residents' attitudes

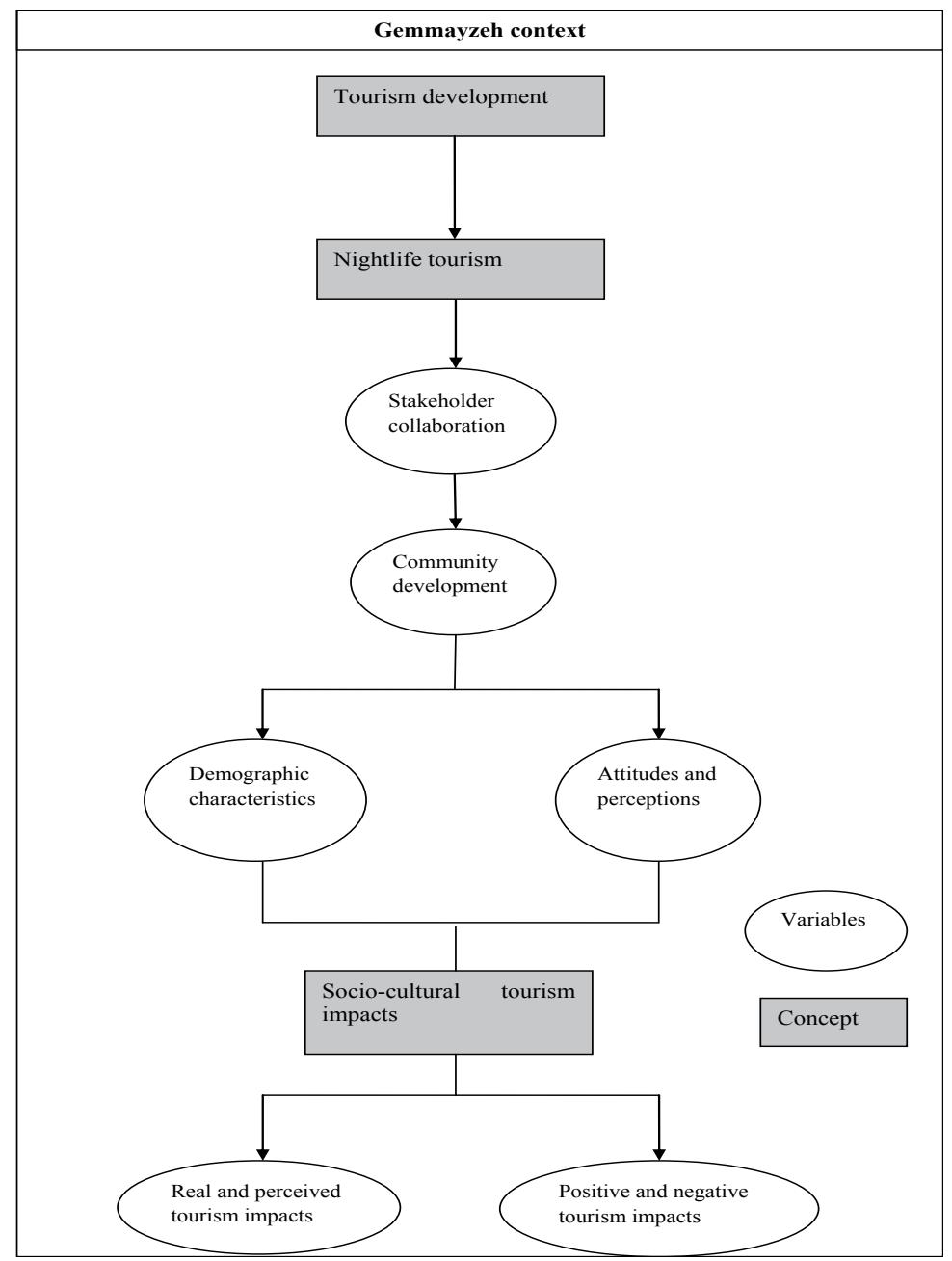

Figure 4: Conceptual framework of tourism development and socio-cultural tourism impacts. 
Citation: El Maalouf H, Ghadban S, Shames M (2015) Nightlife Tourism: A Blessing or a Curse for Host Communities?"A Case Study on Gemmayzeh, Lebanon". J Tourism Res Hospitality 4:2

doi:http://dx.doi.org/10.4172/2324-8807.1000147

toward their role in tourism planning and development. The attitudes of residents are measured as being negative or positive toward these variables. Studying the relations between the variables as shown in Figure 4 in Gemmayzeh context, has allowed the researchers to formulate four main hypotheses:

$\mathbf{H}_{1}$ : The increasing negative impacts of tourism in Gemmayzeh have negatively affected the perceptions of residents toward tourism development in general.

H2: The negatively perceived tourism impacts have contributed local residents to reject nightlife tourism development in Gemmayzeh.

$\mathbf{H}_{3}$ : Since nightlife tourism attracts young visitors, it is hypothetical that young residents (20-30 years old) have accepted nightlife tourism in Gemmayzeh more than older residents.

$\mathbf{H}_{4:}$ The higher the educational attainment of local residents, the more they tend to support tourism development in Gemmayzeh.

In order to be able to answer the research questions and test the formulated hypotheses, a Researcher Administered questionnaire was conducted with 50 local residents in Gemmayzeh. This type of questionnaire is effective and has accurate results since the interviewer can clarify questions for interviewees face-to-face, ensure completion of questions and provide a higher response rate [39]. Quota sampling was utilized for sample selection; this method is defined as a nonprobability sampling technique wherein the assembled sample has the same proportions of individuals as the entire population with respect to known characteristics, traits or focused phenomenon [40]. The selected respondents were permanent residents of the area who represent $70 \%$ (1,400 residents) of the total population in Gemmayzeh. Therefore, the sample represents $5 \%$ of the targeted population. Moreover, respondents were surveyed in different locations in Gemmayzeh mostly in Rue Gouraud and at different periods of the day.

The questionnaire was formulated based on reviewing the different concept indicators and a preliminary analysis of the current tourism situation in Gemmayzeh. Some of the survey questions were the same as those developed by Muganda et al (2013) in their study entitled "The Role of Local Communities in Tourism Development: Grassroots Perspectives from Tanzania” already discussed in the literature review.

The data obtained was analyzed using descriptive statistics and the SPSS. Chi Square test (two way contingency table) was conducted. The Chi Square is a statistical test commonly used to compare observed data with data expected to be obtained according to a specific hypothesis (Black, 2010; McClave, 2014). The Chi square test is therefore used to test a relation between two independent variables that enable the researchers to validate or reject the expected outcomes.

\section{Findings}

\section{Socio Demographic Characteristics of the Surveyed Respondents}

Table 1 represents the socio-demographic characteristics of the surveyed respondents. The age group ranged between 20-30 years (young population) occupies the highest percentage in the sample. The percentages of the two age groups below 20 and between 30 and 50 are distributed almost equally. Only one of the respondents was aged above 50 . This small representation in the sample can be illustrated by
Table 1: SPSS results for the respondent's personal profile $(n=50)$

\begin{tabular}{|c|c|c|c|}
\hline Variable & Category & Frequency & Percent \\
\hline \multirow{4}{*}{ Age } & Under 20 & 13 & 26 \\
\hline & $20-30$ & 20 & 40 \\
\hline & $30-50$ & 16 & 32 \\
\hline & Above 50 & 1 & 2 \\
\hline \multirow{2}{*}{ Gender } & Male & 26 & 52 \\
\hline & Female & 24 & 48 \\
\hline \multirow{4}{*}{ Job status } & Top management & 7 & 14 \\
\hline & Middle management & 22 & 44 \\
\hline & No managerial position & 11 & 22 \\
\hline & No job & 10 & 20 \\
\hline \multirow{5}{*}{ Income } & $\$ 400$ & 4 & 8 \\
\hline & $\$ 400-800$ & 12 & 23 \\
\hline & $\$ 800-1500$ & 12 & 23 \\
\hline & More than $\$ 1500$ & 16 & 31 \\
\hline & N/A & 6 & 15 \\
\hline \multirow{3}{*}{$\begin{array}{l}\text { Highest } \\
\text { completed level } \\
\text { of education }\end{array}$} & Post-graduate & 11 & 22 \\
\hline & Graduate & 32 & 64 \\
\hline & Secondary & 7 & 14 \\
\hline
\end{tabular}

the fact that the majority of people corresponding to this age category have left Gemmayzeh searching for better environmental conditions. Both genders are somehow equally represented in the sample (males $52 \%$ and females $48 \%$ ). As for the job status, the survey covered different levels of jobs. However, it shows a preponderance of middle management positions (44\%), followed by non-managerial positions and only $20 \%$ were unemployed. The average income level for the majority of respondents (46\%) is $400 \$-1500 \$$. A good percentage of respondents have an income level of more than $\$ 1500$. Meaning high purchase power compared to the minimum wage in Lebanon. The majority of participants $(64 \%)$ have graduate degree.

\section{Local Residents' Involvement in Tourism Development in Gemmayzeh}

The overall results in Figure 5 and 6 reveal that what is perceived and desired from the local residents is not reflected by the reality on the field. In accordance with Figure 5, 76\% of the respondents are willing to participate in tourism development in Gemmayzeh, while only $22 \%$ are actually taking part of this development. These findings confirm that the initiatives of local residents to be involved in tourism planning and development have failed over the stages of nightlife tourism development in Gemmayzeh. Furthermore, another interpretation can be drawn here is that despite all the failed attempts of local residents, they are still highly willing to participate and take an effective role. On the other hand, based on the above figure, it is assumed that tourism stakeholders in Gemmayzeh are not willing to involve local residents in the development strategy of the tourism area since their benefits and interests contradict with those of residents especially for the business owners. The reasons behind the unwillingness of $24 \%$ of respondents to participate in tourism development is either due to the many problems the local residents are facing with regard to the unplanned nightlife tourism development in their region and the conflicts with tourists and pubs owners, or they simply consider that their participation will not improve or change tourism development in the area. Tourism can be differently defined by different tourism stakeholders. The definition of tourism from the perspective of local residents and their perceived role in tourism development change with the changing tourism 
destination and the type of tourism developed [43]. Figure 6-a shows that $50 \%$ of the respondents perceived that they should take leading roles as workers at all levels. Followed by $34 \%$ who see that the appropriate role should be sharing ideas in the decision making process of local tourism development, while only $6 \%$ consider that they should not participate by any means. However, contrary to the residents' perceptions of their role, Figure 6-b illustrates that out of the 11 respondents who are participating in tourism development in Gemmayzeh, $61.5 \%$ are taking responsibilities mainly as workers (waiters and waitresses). 23.1\% are sharing information and only $7.7 \%$ have the power to actually take decisions and influence directly the development process of the area. Again, what is perceived as the appropriate role here is not enhanced by real responsibilities on the field. The result with 8 respondents taking responsibilities as Compatible with the fact that $90 \%$ of the local residents work outside the district of Gemmayzeh. Furthermore, the result of the varying roles of local residents in tourism development is enhanced by the findings of Mannigel (2008). Therefore, the lack of involvement of local residents in tourism development of their own area has negatively affected the community's development in Gemmayzeh As suggested by "community development help communities solve problems, take decisions successfully and use resources to develop tourism" which was not recognized in the case of Gemmayeh.

Since the aim of the study is to discover and assess the type

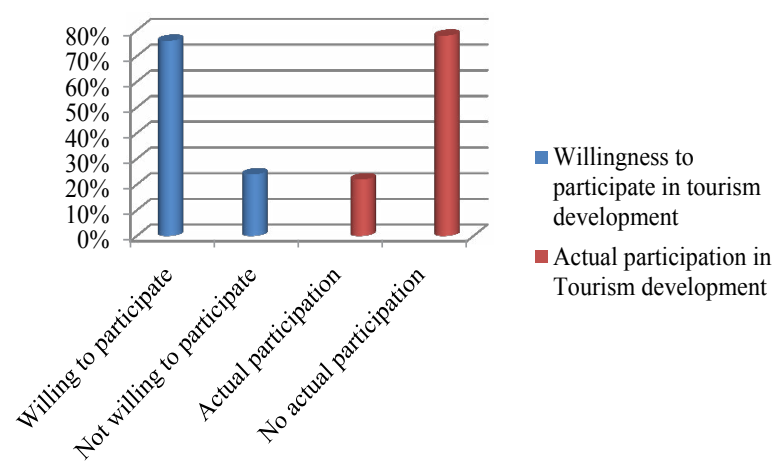

Figure 5: Respondents' willingness to participate versus their real participation. (Respondents were asked about their perceived role in tourism development versus their real level of participation).

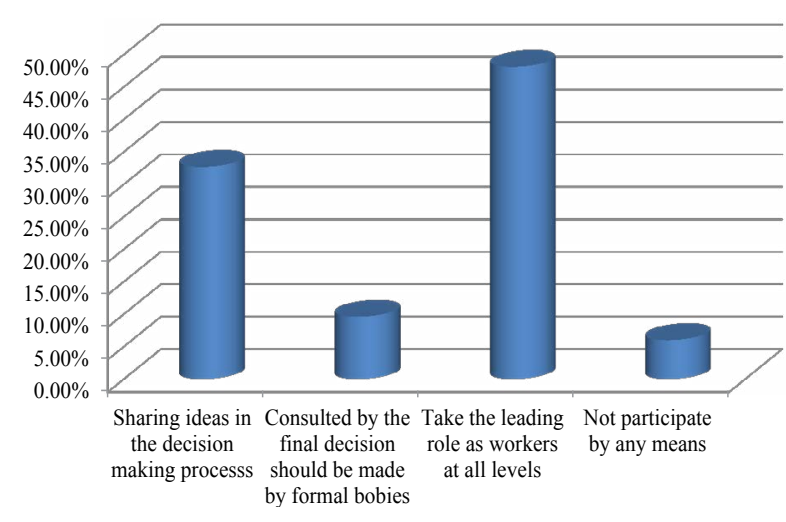

Figure 6a: Perceptions toward residents' role in tourism development

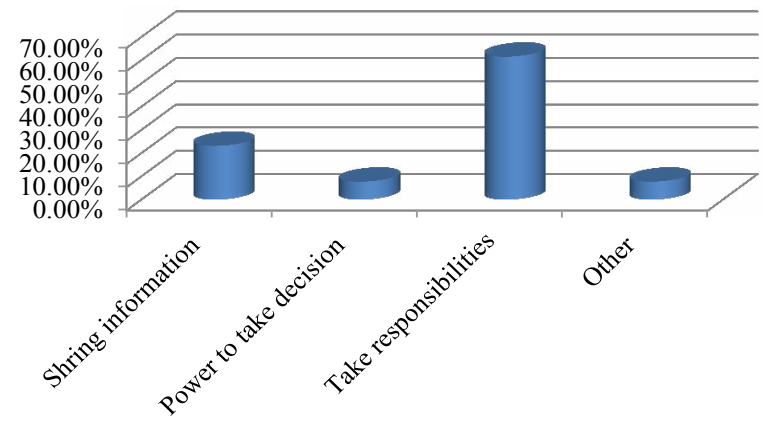

Figure 6b: The real participation of residents in tourism development of Gemmayzeh

of involvement of local community in tourism planning and development. The above results demonstrated that local residents have no effective role in the development of tourism in their area and the type of involvement has limited impacts on the tourism performance in Gemmayzeh. Moreover, their role cannot be taken as evidence in generalizing the effective role local residents should take in nightlife tourism development. Although, the findings reveal that even when local residents are annoyed by tourism in their region, they tend to reduce its impacts by trying to be involved at high level of tourism development.

\section{Residents' Attitudes toward Tourism Impacts in Gemmayzeh}

It is assumed that in the case of Gemmayzeh, the unguided nightlife tourism development has brought many negative impacts to the society. Nevertheless, it is assumed that despite all these negative impacts, tourism did however bring some positive impacts to the well being of the communities. Table 2 shows the percentages of respondents who agreed, disagreed or were neutral toward the given socio-cultural tourism impacts. The Table demonstrates that the majority of respondents consider that tourism in Gemmayzeh has contributed to negative impacts. The problems residents have been facing in Gemmayzeh mainly with the tourism businesses and visitors have negatively affected the region instead of improving it. Poverty reduction and raising the standards of living generally appear within a tourism destination when tourism provides residents the opportunities to work and be involved in community development; the thing that did not happen in Gemmayzeh. Still residents are involved in direct conflicts with visitors who are not being able to respect the traditions of the area, so residents cannot see positive impacts for tourism. As for the variables of social equity and providing job opportunities, the above table shows that the majority of respondents were neutral toward the impacts of tourism with regard to these two variables. Being neutral raise the question of whether tourism has really created job opportunities for residents in Gemmayzeh and has consequently contributed to social equity. Or it is simply that residents are being provided part time work which cannot be considered as real job opportunity.

As for the variables of social equity and providing job opportunities, the above table shows that the majority of respondents were neutral toward the impacts of tourism with regard to these two variables. Being neutral raise the question of whether tourism has really created job opportunities for residents in Gemmayzeh and has 
Citation: El Maalouf H, Ghadban S, Shames M (2015) Nightlife Tourism: A Blessing or a Curse for Host Communities?"A Case Study on Gemmayzeh, Lebanon'. J Tourism Res Hospitality 4:2

consequently contributed to social equity, or simply that residents are being provided part time work which cannot be considered as real job opportunity.

Figure 7 demonstrates that the majority of respondents (78\%) perceive the overall socio-cultural tourism impacts as negative (Figure 7). The reason behind this high percentage is due to the fact that since Lebanon is considered as collectivistic society and since nightlife tourism has negatively affected local residents in Gemmayeh, it was argued by the whole community that the socio-cultural tourism impacts are negative. Therefore, the researchers have attained their objectives in studying and exploring the attitudes of residents toward tourism development and its impacts on the society.

Results of the SPSS have also revealed that $90 \%$ of the respondents strongly agreed that they are in fact unhappy with the tourism activities. This finding affirms The theory of [45] who stated that the attitude of residents toward tourism development is negative when residents are dissatisfied by tourism development. Therefore, for a better understanding of the relation between the socio-cultural tourism impacts and residents' attitudes toward these impacts, the first hypothesis was tested (Table 3).

Table 3 shows that the test value " 17.195 " is greater than the critical value "9.4877", which means that the hypothesis is accepted; The increasing negative impacts on Gemmayzeh local residents (which can be measured by the relation between the residents and tourists as well as business owners and the impacts of tourism development) have negatively affected their perceptions toward tourism development. Furthermore, results of the chi square test (Table 4) which test the relation between the negatively perceived tourism impacts and their rejection of nightlife tourism development, demonstrate that

Table 2: Local resident's view on the socio-cultural impacts of tourism in Gemmayzeh.

\begin{tabular}{|c|c|c|c|}
\hline Variables of Socio-cultural tourism impacts & Yes & No & Neutral \\
\hline $\begin{array}{c}\text { Tourism in Gemmayzeh has contributed to } \\
\text { poverty reduction }\end{array}$ & $24 \%$ & $58 \%$ & $18 \%$ \\
\hline $\begin{array}{c}\text { Tourism in Gemmayzeh has raised the } \\
\text { standards of living }\end{array}$ & $28 \%$ & $58 \%$ & $14 \%$ \\
\hline $\begin{array}{c}\text { Tourism in Gemmayzeh has contributed to } \\
\text { social equity }\end{array}$ & $38 \%$ & $22 \%$ & $40 \%$ \\
\hline $\begin{array}{c}\text { Tourism in Gemmayzeh provided job } \\
\text { opportunities for local people }\end{array}$ & $16 \%$ & $10 \%$ & $74 \%$ \\
\hline $\begin{array}{c}\text { Tourism in Gemmayzeh hascontributed to } \\
\text { social interaction in Gemmayzeh }\end{array}$ & $20 \%$ & $44 \%$ & $36 \%$ \\
\hline
\end{tabular}

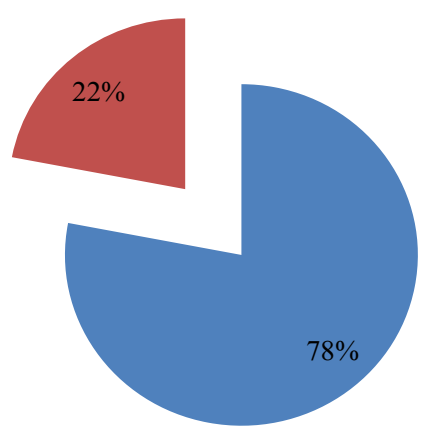

- Negative

- Positive

Figure 7: Residents' perceptions toward the socio-cultural tourism impacts in Gemmayzeh.
${ }^{1}$ The degree of freedom is calculated as following:(K-1) (K-1), K stands for the possibilities of each question ( 5 possibilities for the first variables and two possibilities for the second variable) and 1 stands for the number of options respondents can select which is both questions is one (McClave et al, 2014). Then DF in this case will be (5-1) $(2-1)=4$

Table 3: Results for the Chi square test on the relation between the socio-cultura tourism impacts in Gemmayzeh and the residents' perception toward tourism development.

\begin{tabular}{|l|c|c|c|c|}
\hline Test variables & a & DF $^{1}$ & $\begin{array}{c}\text { Critical } \\
\text { value }\end{array}$ & Test value \\
\hline $\begin{array}{c}\text { Socio-cultural } \\
\text { tourism impacts and } \\
\text { perceptions toward } \\
\text { tourism development }\end{array}$ & 0.05 & 4 & 9.4877 & 17.195 \\
\hline $\begin{array}{l}\text { *DF stands for the degree of freedom which is used along with the critical } \\
\text { value to determine the acceptance or rejection of the alternative hypothesis. } \\
\text { If the test value is greater than the critical value, the alternative hypothesis } \\
\text { (which assumes that there is a relation between the variables being tested) is } \\
\text { accepted. }\end{array}$ \\
\hline
\end{tabular}

Table 4: Results for the Chi square test on the relation between local resident's acceptance of tourism development and their perceptions toward its impacts.

\begin{tabular}{|c|c|c|c|c|}
\hline Test variables & $\boldsymbol{\alpha}$ & DF & $\begin{array}{c}\text { Critical } \\
\text { value }\end{array}$ & Test value \\
\hline $\begin{array}{c}\text { Perceptions toward tourism impacts and } \\
\text { acceptance of tourism development }\end{array}$ & 0.05 & 1 & 3.8415 & 0.002 \\
\hline
\end{tabular}

the second hypothesis is rejected $(0.002<3.8415)$. Contrary to the study of Johnson and Snepenger (2003) in this research, results have demonstrated that despite the negative perception of residents toward tourism impacts in Gemmayzeh, the majority of respondents accepted the development of nightlife tourism but not in the same way it has been developed for many years. On the opposite, the interpretation could be that residents have refused this development for years and have attempted to stop it but they couldn't because of many other uncontrollable factors such as the business owners acts to continue operating in Gemmayzeh, and the lack of law enforcement which can support the residents' opinion. Hence, their acceptance could be justified by the fact that they couldn't resist nightlife tourism development so they simply accepted the latter without real interest in nightlife tourism.

\section{Nightlife Tourism and the Varying Perceptions of Local Residents}

Figure 8 shows that $58 \%$ of the participants agreed that the best type of tourism to be developed in their area is in fact nightlife tourism. However, they mainly disagreed with the way this form has been implemented affecting their region and their way of living. This finding also reveals that residents are aware about the potentials of Gemmayzeh as a main hotspot for nightlife tourism suggesting that cultural tourism can also be developed in parallel in the same region reflecting the authenticity and traditionalism of this particular area of Beirut. Therefore, the interpretation in the above section which States that residents surveyed has accepted nightlife tourism just because they couldn't stop its development is not applicable in the case of Gemmayzeh. Regarding the relation between residents' age and acceptance of nightlife tourism, Table 5 shows that the third hypothesis is accepted (the test value is greater than the critical value). Younger residents tend to accept nightlife tourism more than older ones. For instance, Figure 9 shows that the majority of respondents, whose age vary between 20-30 years old, have accepted nightlife tourism as a major type of development in Gemmayzeh, while it has been rejected by the majority of respondents whose age vary between 


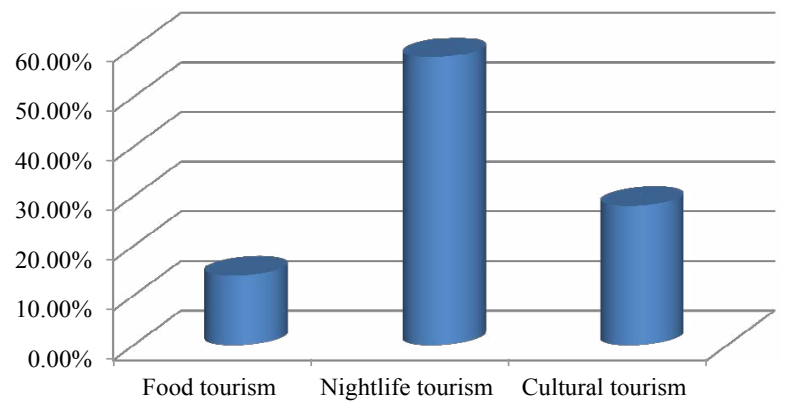

Figure 8: Resident's opinion about the most appropriate type of tourism to be developed in their region.

Table 5: Results for the Chi square tests on the relation between acceptance of nightlife tourism and variables of respondent's socio-demographic characteristics.

\begin{tabular}{|c|c|c|c|c|}
\hline Test variables & $\boldsymbol{\alpha}$ & DF & $\begin{array}{c}\text { Critical } \\
\text { value }\end{array}$ & $\begin{array}{c}\text { Test } \\
\text { value }\end{array}$ \\
\hline $\begin{array}{c}\text { Acceptance of nightlife tourism and } \\
\text { residents' age }\end{array}$ & 0.05 & 3 & 7.8147 & 10.118 \\
\hline $\begin{array}{c}\text { Perception toward tourism development } \\
\text { and residents' educational level }\end{array}$ & 0.05 & 2 & 5.9915 & 1.326 \\
\hline
\end{tabular}

Bar Chart

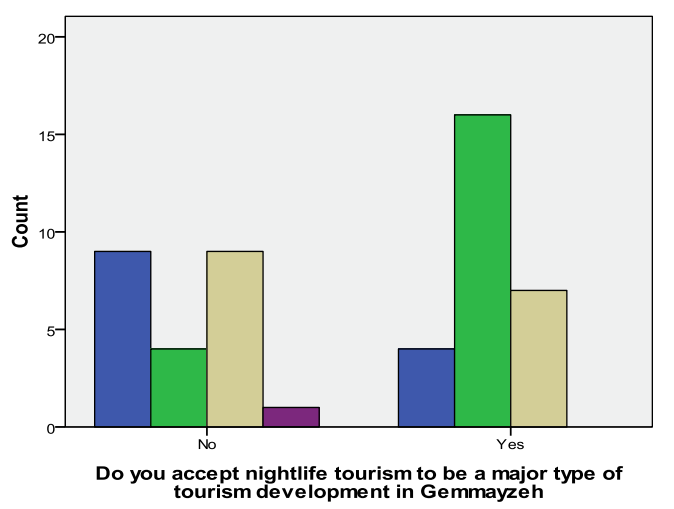

Figure 9: Relation between residents' age and their acceptance of nightlife tourism in Gemmayzeh.

\section{0-50 years old.}

However, as for the relation between residents' educational level and their support for tourism development in Gemmayzeh, Table 5 shows that this hypothesis is rejected. Despite their high education, the majority of the participants' views this tourism as negative and do not support it. This explains why the theory of Johnson and Snepenger (2003), is not applicable herein since the type of tourism is different and the nature of the problem related to unregulated tourism development is more complex which has nothing to do with the level of education of local residents who are not part of the tourism development and the decision making process.

\section{Discussion and Conclusion}

The aim of conducting this study was to provide a clear view of nightlife tourism in Gemmayzeh taking into consideration the resident's point of view which is affected by the unregulated and unguided tourism planning and development. To this end, 50 local residents were sampled and interviewed using the researcher administered questionnaire (representing $5 \%$ of the total permanent residents in Gemmayzeh). The survey analysis using the SPSS revealed several important conclusions with regard to the role of residents in tourism development as well as the attitudes and perceptions toward the socio-cultural tourism impacts. Some of the study results oppose with the developed body of literature while other findings complement and confirm previous published studies.

The willingness of local residents to be more involved in the development of their region's tourism plan and decision making process have failed over the years as the tourism stakeholders have not reached for their help. Hence, the lack of cooperation between the residents and other stakeholders involved did not help in solving the tourism problems. This finding complements The results of [47]. The cultural system of the community in Gemmayzeh will remain threatened by the lack of resident's involvement if no effective policies will be developed by the government and the business owners to enhance the role of residents. For that reason, it is suggested to develop communication strategies such as awareness raising campaigns, trainings, workshops for all the stakeholders involved about the risks of the ineffective collaboration. Monthly meetings and discussions could be held to develop and agree on the terms of collaboration. Furthermore, it is recommended for tourism stakeholders to develop strategies and tourism policies based on the rationality of stakeholder theory, stakeholder mapping and analysis (SDC Political Economy and Development, 2011) and community development approach. Local residents should be involved in all tourism development levels with their utilized skills and knowledge, and consider the success of tourism in the area. This could be achieved through the effective implementation of stakeholder participatory approach, where stakeholders meet, communicate their ideas, develop scenarios and create appropriate strategies for implementation on the field Plieninger et al, 2013).

This study shows that the increasing negative impacts of tourism on the local residents were reflected by a negative perception and discomfort by the whole community residents ( $78 \%$ of the respondents surveyed) from the tourism activities taking place in the region. Hence, any attempt to reach local residents and satisfy their needs should target the whole community and not individuals. On the other hand, the SPSS results showed that the acceptance of nightlife tourism development was not affected by the negative perceptions of residents. Instead, the majority of residents have no problem with nightlife as a major type of tourism to be developed in Gemmayzeh. This leads to conclude that the negative impacts of tourism development are not always related to the type of tourism, but to the way this type is being developed and implemented, while realizing that different age groups tend to prefer different types of tourism. Based on this, it is suggested to have reform plans for the development of nightlife tourism in Gemmayzeh involving additional policies and regulation. This includes a legislative framework that takes into consideration the nature of nightlife tourism in Gemmayzeh and the needs of residents. For example, maintaining a balanced nightlife tourism development while developing other forms of tourism, such as, cultural and culinary tourism to protect the traditionalism of the area, while getting a bigger participation from the local community. Discussing the tourism impacts in Gemmayzeh within the peculiarities of Beirut reveals many important implications. Beirut is the center of the country's most social, economic, political and cultural activities [48]. It is well 
Citation: El Maalouf H, Ghadban S, Shames M (2015) Nightlife Tourism: A Blessing or a Curse for Host Communities?"A Case Study on Gemmayzeh, Lebanon". J Tourism Res Hospitality 4:2

known for its nightlife tourism, where it was cited by the international media as the number one place in the world for its vibrant nightlife [49]. The city is also considered a potential destination for different types of tourism including business tourism, leisure tourism, culture tourism, sport tourism and many others. This variety and cultural diversity constitute challenges as well as opportunities for the tourism competitiveness in Gemmayzeh. The challenges for stakeholders consist in being able to reflect an image that can complement the overall tourism image of Beirut or to create a separate and unique identity especially that the cultural diversity of Beirut may oppose to the one of Gemmayzeh. However, the opportunities lie in the fact that Gemmayzeh is located in Beirut giving the city uniqueness and the potential for the development of various types of tourism. It is worth mentioning that after one year of conducting this study, local residents are facing the same problems with tourists and tourism businesses even after the efforts of the Minister of Tourism and Beirut Municipality to improve security in the area. The implementation of sustainable tourism and its principles can be a solution for this problem. It is suggested to include the concept of sustainable tourism in the development plans of the region. Finally, the limitations of the study should be discussed with regard to future research. Additional studies are needed to analyze the impacts of Beirut socio-cultural diversity as an additional factor that can affect the perceptions of local residents. Further researches targeting a wider sample of local residents in Gemmayzeh are to be conducted. The opinions of other stakeholders, mainly tourists, are also another area of study for future research. The attitudes of local residents toward tourism development should be examined over the stages of tourism area life cycle Further researches should also be conducted to explore the tourism potentials of Gemmayzeh and its abilities to target new visitors through wellorganized marketing strategies. This includes scanning the available resources in Gemmayzeh that can contribute for the development of other types of tourism. Furthermore, due to the limited sources of information about Gemmayzeh and nightlife tourism in Lebanon, it is also suggested to create a tourism research center accessible to researchers, tourists and Lebanese citizens.

\section{Acknowledgement}

This study was conducted under the support of the Lebanese Universityfaculty of Tourism and Hospitality Management. Special thanks go to Elie Nassa -the Mayor and Head of the Residents' Committees and to Beirut municipality for providing us with the required information. Our appreciation also goes to the local community residents who participated in the survey questionnaire.

\section{References}

1. Andrey J (2013) Tourism area life cycle theory.

2. Andriotis K, Vaughan RD (2003) Urban residents' attitudes toward tourism development: The case of Crete. J Travel Res 42: 172-185.

3. Ap J, Crompton JL (1993) 'Residents' strategies for responding to tourism impacts.' J TravelRes 32: 147-150.

4. Aref F, Gill SS, FarshidA (2010) Tourism development in local communities: as a community development approach. JAm Sci6:155-161.

5. Atoui F (2004) Tourism and touristic and hotel legislation in Lebanon and Arab countries. Halabi rights publication 145-163.

6. BankMed (2013) Analysis of Lebanon's travel and tourism sector.

7. Beirut municipality (2014) Map of Gemmayzeh district. Personal communication.

8. Black K (2010). Applied business statistics-making better business decisions. International student version 6: 344-515.

9. Bogahawatte C (2013) Socio-cultural impacts of tourism.
10. Bramwell B, SharmanA (1999) Collaboration in local tourism policymaking. Ann Tourism Res 26: 392-415.

11. Byrd TE (2007) Stakeholders in sustainable tourism development and their roles: applying stakeholder theory to sustainable tourism development. Research study.

12. Bryson MJ (2004)What to do when stakeholders matter-stakeholder identification and analysis techniques. Public management review 6: 21-53.

13. Byrd E T, Gustake L (2007) Using decision trees to identify tourism stakeholder: The case of two Eastern North Carolina counties. Tour Hosp Res 7: 176-193.

14. Calafat A, Nicole B, BelliM, Karen H, Kokkevi A et al. (2010) Tourism, nightlife, and violence: a cross cultural analysis and preventive recommendations. Valencia, Spain 10-43.

15. Campo D (2008) The Entertainment Zone: Unplanned Nightlife and the Revitalization of the American Downtown. J Urb Des 291-310.

16. Chaiklin H (2010) Attitudes, behaviors and social practice. J Social SocWelf 38: 31-54.

17. Davie FM (1987) Maps and the historical topagraphy of Beirut.

18. Demaline K (2011) The quality of life in community district 3: nightlife impacts.

19. European communities (2003)A manual for evaluating the quality performance of tourist destinations and services. Enterprise DG Publication, Luxembourg.

20. Executive magazine (2008) Nightlife-taming the block rock, sleepy area turned party central pits residents against revelers.

21. Fredline L, Deery M, Jago $L$ (2006) Development of a scale to assess the social impacts of tourism within communities 6: 01-07.

22. Freeman RE (1994)The politics of stakeholder theory: some future directions 4: 409-421.

23. Goeldner RC, Ritchie BR (2012) Tourism: Principles, Practices, Philosophies, 12th Edition.

24. Golzardi F, Sarvaramini S, Sadatasilan K, Sarvaramini M (2012) Residents attitudes toward tourism development: a case study of Niasar, Iran. Research J ApplSciEngTech4: 863-868.

25. Gun C, Var T (2007) Tourism planning: basics, concepts, cases. London, Routledge, $4^{\text {th }}$ edition.

26. Gursoy D, Jurowski C, Uysal M (2002) Resident attitudes: a structural modelling approach.' Ann Tour Res Vol. 29: 79-105.

27. Halh TD (2014)Inter-cultural communication, cultural context, 48-54.

28. Harry CT, Michele JG A theory of individualism and collectivism. London, British library.

29. Hayden H, O’Brien TÓ,Rathaille M (2005)User survey at Waterford Institute of Technology Libraries. 106: 43-57.

30. Hume T (2012) Beirut: the middle east's party capital.

31. IDAL (2014) Tourism, IDAL Invest in Lebanon.

32. Johnson DJ, SnepengerJD (2003) Residents' perceptions of tourism development over the early stages of the TALC.222-373.

33. Khadra A (2014) The capital Beirut.

34. Kim K (2002)The effects of tourism impacts upon quality of life of residents in the community. Blacksburg, Virginia 01-200.

35. Kothari RC (2004)Research Methodology: Methods and Techniques. University of Rajasthan, India, second edition01-22.

36. Ko WD,StewartPW (2002) A structural equation model of residents' attitudes for tourism development. Tourism management23: 521-530.

37. KreagG (2001) The impacts of tourism. Minnesota Sea Grant, No.13.

38. Lankford SV (1994) Attitudes and Perceptions toward tourism and Rural Regional Development. J Travel Res 32: 35-44.

39. Lebanon articles (2014) 10 contemporary art galleries in Beirut you should visit.

40. Mathieson A, Wall G (1982) Tourism: economic, physical and social impacts. Longman, Harlow.

41. McClave TJ, Benson GP, Sincich TT (2014) Statistics for business and 
Citation: El Maalouf H, Ghadban S, Shames M (2015) Nightlife Tourism: A Blessing or a Curse for Host Communities? “A Case Study on Gemmayzeh, Lebanon". J Tourism Res Hospitality 4:2

economics, 12/E

42. Monterrubio C, Juan J,Bello A (2010) Local community attitudes towards the impact of tourism on prostitution. J Tour12: 13-20.

43. Muganda, Michael. Sirima, Agnes. Ezra, Marwa, Peter (2013) The role of local communities in tourism development: grassroots perspectives from Tanzania. J Hum Ecol 41:53-66.

44. Nadine K (2010) Gemmayzeh in crisis.

45. Nassar E,(2014)Mayor of Gemmayzeh and head of the residents' committees, personal communication.

46. Palomino B, Lopez L (2003) Impacts of mass tourism on local communities and the new phenomenon of colonization: a case study. Majorca 06-29.

47. Plieninger T, Bieling C, Ohnesorge B, Schaich H, Schleyer C et al. (2013) Exploring futures of ecosystem services in cultural landscapes through participatory scenario development in the SwabianAlb, Germany. Ecology and society $18: 3$.

48. Poynter JM (2011) How to Research and write a thesis in Hospitality and Tourism. New York: University Press.

49. PresenzaA (2007) The performance of a tourism destination. Who manages the destination? Who plays the audit role?

50. Rainey V, Semaan E (2014) Gemmayzeh Art Deco House demolition rouses ire. The daily star 3.
51. 1.Saftic D,Težak A, Luk $N$ (2011) Stakeholder approach in tourism management: implication in Croatian tourism. 30th International Conference on Organizational Science Development future organization.

52. SDC Political Economy and Development (2011) Stakeholder analysis and mapping. PED Network, PED Basic Tools.

53. Sekaran U, Wiley J (2009) Research methods for business, A skill building approach. New York: AU.

54. Stevenson L (2010) Private sector and enterprise development: fostering growth in the Middle East and North Africa. Egypte, Cairo206-2018.

55. Topalian N (2010) Lebanon Gemmayze neighborhood quite for now. Al Shorfa.

56. Tosun C (2002) Host perceptions of impacts-a comparative tourism study. Ann Tour Res 29: 231-253.

57. UNHCR (2014) Syrian regional refugee response.

58. WTTC (2014) Travel and tourism economic impact.

59. WTTC (2014) Economic impact 2014, Lebanon.

60. Zaei EM(2013) The impacts of tourism industry on host community. Eur J TourHosp Res 1: 12-21.
Author Affiliation

Department of Tourism and Hospitality Management, Lebanese University, Beirut, Lebanon

Submit your next manuscript and get advantages of SciTechnol submissions

* 50 Journals

* 21 Day rapid review process

* 1000 Editorial team

* 2 Million readers

* Publication immediately after acceptance

* Quality and quick editorial, review processing

Submit your next manuscript at • www.scitechnol.com/submission 